ducing alcoholic fermentation; second, as the mycelium, producing acid, without the intervention of vinous fermentation; and, third, on the exhaustion of the acid or sugar, inducing putrefactive decomposition. I might observe, that another peculiarity of the fungus is that of retaining, under certain conditions, a uniform state of development. Thus, I have found the nuclei produced by the bursting of yeast-cells ("globulin" of Turpin ?) to be capable of almost endless reproduction as nuclei, having a diameter of 10,000 th of an inch. In this form they are possibly received from the air into the circulation, and may give rise to sarcina in the kidney (for sarcina is now thought, on good grounds, by Mr. Berkeley, to be produced by penicillium or aspergillus). Again, I have seen these nuclei develop into cells, in which form they are also capable of endless extension as yeast. Attaining the higher form of the mycelium, they may be produced indefinitely as the vinegar-plant.

As I have elsewhere endeavoured to show, the whole group of parasitic fungi have origin from one or two common species of mould. Thus the frequency of skin diseases in dirty and ill-ventilated dwellings is no mystery.

In conclusion, I would observe that in the foregoing remarks I do not venture to advocate a theory in favour of a diphtheric parasite. I would merely say that, in the presence of so much contrariety of opinion, it were well that further inquiries should be instituted; for while it is fully admitted that the disease is infectious, it is by no means proved what the morbific agent is. I am, Sir, your obedient servant,

King's Lymn, Feb. 1859. JoHY Lowe, M.D.

P.S.-I observe that Dr. Harley proposes to institute experiments as to the effects of fungi in the blood, by injecting the mycelium and spores into the vessels. Now, as these have a diameter greater than that of blood-globules, they would probably be arrested in the capillaries, and there undergo disintegration, or else excite local inflammation. Might I suggest, that the value of the experiments would be enhanced by making use of the fungus in a state wherein the diameter of the cellules is less than that of the blood-corpuscles-e. $g .$, yeast, exposed for a lengthened period to the atmosphere, and which has become pulverulent by the bursting of the cells, and escape of the contained granules, which have a diameter of from the 10,000 th to 7000 th of an inch.

\section{THE ANATOMY ACT.}

[NOTE FROM CHARLES HAWKINS, ESQ.] To the Editor of The Lancet.

SrR,-It is not my intention to enter into any discussion at present with regard to the working of the Anatomy Act. But as I am sure you would not wish that your journal should contain any incorrect information, I am led to notice the following statement, made by an anonymous correspondent, in THE LAXCer of the 26th ult.:-

"In the medical school I attend, there are about two hundred students engaged in the pursuit of practical anatomy and, up to this time, only twenty-five subjects have come in."

You may state, Sir, on my authority, if you think it worth while, that there is no school in London with even one hun. dred pupils that has not had upwards of twenty-five subjects; indeed a school with less than one hundred pupils has had more than twenty-five. There is no school in London with two hundred registered pupils.

$$
\text { I am, Sir, your obedient servant, }
$$

Savile-row, Burlington-gardens, CHAS. HAWKINS, F.R.C.S., February, 1859 Inspector of Anatomy.

\section{THE NEW MILITARY MEDICAL SCHOOL. To the Editor of The LANCET.}

SIR,-I am delighted to see that you bave called attention, by the insertion in your journal of 26 th ult. of the very sensible letter of "A Last Year's Man," to the scheme proposed by Miss Nightingale of sending all the young army surgeons to school. "When a lady's in the case, all others must give place;" but, in my opinion, the lady herself is out of place in a question such as the present, where she dabbles in a matter that she cannot understand. Soup kitchens and extra issues are her province, and for those duties no woman on earth is better fitted; but for drawing out of schemes for military medical education she is totally unsuited, and no better proof of this can be given than by referring to her contemplated intention of founding this school for the teaching of clinical medical surgery. She has hitherto had her own way, uncontrolled; but licenee enough has certainly been given to this good lady, and as she seems now bent on going from the sublime into the ridiculous, let some limit be placed on her ideas.

This school may be all very pretty in theory, but practically it would be a perfect nuisance. It would deter candidates from entering, for the desirable men, the really well-educated, would not stand this nonsense. I know that there is nothing which the army surgeon can be taught at home that he cannot learn equally well whilst a student, without anything more than a local professorship, such as that at Dublin, and that no special school is needed.

March, 1859 . I am, Sir, your obeäient servant,

A Stafr-SURgeon.

\section{NOVEL SUBSTITUTE FOR A FEMALE CATHETER. \\ To the Editor of The Lancet.}

SIR,-Should you deem the following incident of sufficient interest to your numerous readers, you will do me the favour to give it a place in your journal:-

Un June 3rd, 1858, I made a professional visit to a female patient who was suffering from a severe attack of typhus fever. Upon inquiry, I learnt that she had passed scarcely any urine for several hours; and, on examination, found an enormous abdominal enlargement from distension of the bladder. I at once determined, if possible, to empty it; but being about six miles from home, and having no catheter with me, I resolved on trying to construct one with a quill. I obtained a knittingneedle with a circular head, passed it through a piece of quill,
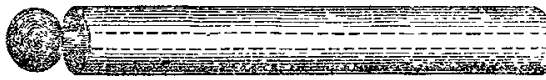

and, by keeping them in apposition, readily introduced them into the bladder, and succeeded, by forcing the head of the needle slightly beyond the end of the quill, in emptying it. I am, Sir, your obedient servant,

Chichester, February, 1859. AlLEN DUEE, M.D.

\section{THE NEW MEDICAL ACT.}

\section{To the Editor of THE LANCET.}

SIR,-Perceiving by the last number of THE LANCET that a Bill is brought into Parliament to amend the Medical Act of IS58, may not the "gross monopoly" which you drew attention to in THE LANCET of the 18th of December last, in the appointment of medical officers to the county infirmaries in Ireland, be rectified merely by stating, in Clause 36 of the said Medical Act of last session, that all persons duly registered under that Act are eligible to be appointed as medical officers to all infirmaries, hospitals, or other medical institutions in the United Kingdom; that no one shall hold any of these situations until first registered in accordance with the said Medical Act?

Now that an opportunity occurs to do away with every monopoly, not before provided for, your well-merited influence is looked to to get the defect remedied.

March, 1859. I am, Sir, your obediente servant,
A SUBSCRIBER.

\section{TURNING VERSUS CRANIOTOMY. To the Editor of THE LANCET.}

SIR,-During my stay with a medical practitioner of Rochdale, I was requested, during his absence from home, to attend a Mrs. S-, who lived about two miles in the country. On my arrival, I found her in labour with her seventh ehild. To my surprise and astonishment, on inquiry, I was informed that craniotomy had been performed in all her previous labours by that gentleman. On an examination per vaginam, I found a foot presenting, and that the promontory of the sacrum lessened to some considerable extent the antero-posterior diameter of the pelvis. I experienced no difficulty in the extraction of the head, the chin being well pressed on the chest. A fine child was born alive; they both did well.

Two years afterwards I was summoned again to attend Mrs. S- On examination, I found the head presenting above the pelvic brim, os uteri fully dilated, membranes unruptured. From the facility with which I succeeded in her previous con 